\title{
A comparison of two PCR protocols for the differentiation of Plasmodium ovale species and implications for clinical management in travellers returning
} to Germany: a 10-year cross-sectional study

\author{
Hagen Frickmann ${ }^{1,2^{*}} \mathbb{D}$, Christine Wegner ${ }^{3}$, Stefanie Ruben ${ }^{3}$, Ulrike Loderstädt ${ }^{3}$ and Egbert Tannich ${ }^{3}$
}

\begin{abstract}
Background: To assess the occurrence of Plasmodium ovale wallikeri and Plasmodium ovale curtisi species in travellers returning to Germany, two real-time PCR protocols for the detection and differentiation of the two P. ovale species were compared. Results of parasite differentiation were correlated with patient data.

Methods: Residual nucleic acid extractions from EDTA blood samples of patients with $P$. ovale spp. malaria, collected between 2010 and 2019 at the National Reference Centre for Tropical Pathogens in Germany, were subjected to further parasite discrimination in a retrospective assessment. All samples had been analysed by microscopy and by P. ovale spp.-specific real-time PCR without discrimination on species level. Two different real-time PCR protocols for species discrimination of P. o. curtisi and P. o. wallikeri were carried out. Results were correlated with patient data on gender, age, travel destination, thrombocyte count, and duration of parasite latency.

Results: Samples from 77 P. ovale spp. malaria patients were assessed, with a male:female ratio of about 2:1 and a median age of 30 years. Parasitaemia was low, ranging from few visible parasites up to $1 \%$ infected erythrocytes. Discriminative real-time PCRs revealed 41 cases of P. o. curtisi and 36 cases of P. o. wallikeri infections. Concordance of results by the two PCR approaches was 100\%. Assessment of travel destinations confirmed co-existence of P. o. curtisi and P. o. wallikeri over a wide range of countries in sub-Saharan Africa. Latency periods for the two P. ovale species were similar, with median values of 56.0 days for P. o. curtisi and 58.0 days for P. o. wallikeri; likewise, there was no statistically significant difference in thrombocyte count with median values of $138.5 / \mu \mathrm{L}$ for patients with P. o. curtisi and 152.0/uL for P. O. wallikeri-infected patients.

Conclusions: Two different real-time PCR protocols were found to be suitable for the discrimination of P. o. curtisi and P. O. wallikeri with only minor differences in sensitivity. Due to the overall low parasitaemia and the lack of differences in severity-related aspects like parasite latency periods or thrombocyte counts, this study supports the use of $P$. ovale spp. PCR without discrimination on species level to confirm the diagnosis and to inform clinical management of malaria in these patients.
\end{abstract}

\footnotetext{
*Correspondence: Frickmann@bnitm.de

${ }^{1}$ Department of Microbiology and Hospital Hygiene, External Site

at the Bernhard Nocht Institute, Tropical Microbiology and Entomology, Bundeswehr Hospital Hamburg, Bernhard Nocht Str. 74, 20359 Hamburg,

Germany

Full list of author information is available at the end of the article
}

(c) The Author(s) 2019. This article is distributed under the terms of the Creative Commons Attribution 4.0 International License (http://creativecommons.org/licenses/by/4.0/), which permits unrestricted use, distribution, and reproduction in any medium, provided you give appropriate credit to the original author(s) and the source, provide a link to the Creative Commons license, and indicate if changes were made. The Creative Commons Public Domain Dedication waiver (http://creativecommons.org/ publicdomain/zero/1.0/) applies to the data made available in this article, unless otherwise stated. 
Keywords: Malaria, Plasmodium ovale curtisi, Plasmodium ovale wallikeri, Parasite latency, Epidemiology, Test comparison

\section{Background}

Human Plasmodium ovale spp. malaria is caused by two different sympatric Plasmodium species, namely $P$. ovale curtisi, which was considered the "classic" human pathogen, and $P$. ovale wallikeri, which has been described as a genetically distinguishable variant. Parasitological features such as parasitaemia, 18S rRNA gene copy number, or pan-aldolase activity are similar, with an overrepresentation of infected erythrocytes lacking Schüffner's stippling among $P$. ovale wallikeri isolates [1]. Although the organisms are morphologically virtually indistinguishable and are associated with sympatric ranges through tropical Africa, Asia, and Oceania, considerable genetic differences have been observed between $P$. ovale curtisi and $P$. ovale wallikeri. They do not recombine and are associated with substantial genetic divergence between sexual stage proteins, such as 6-cysteine and proteins containing Limulus coagulation factor $\mathrm{C}$ domains, probably resulting in sexual incompatibility [2]. Phylogenetic separation and diversity of $P . o$. curtisi and $P . o$. wallikeri surface antigens support species status $[3,4]$.

The occurrence of $P . o$. curtisi and $P$. o. wallikeri in returning travellers has been reported from Canada [1], China [5-12], Southern Europe [13, 14], and the UK [15]. A wide range of sub-Saharan Africa has been identified as the major region of $P$. ovale spp. acquisition for Chinese travellers $[8,9,11,12]$, while a majority $(88 \%)$ of returnees to Canada came from Western Africa [1]. Both $P$. ovale spp. have been infrequently reported from Bangladesh [16]; Bioko Island [17], the Comoros Islands [18], Congo-Brazzaville [17], Ethiopia [19, 20], Ghana [21], India [22], the Ivory Coast [16], Kenya [23], Senegal [24, 25], and Uganda [17]. Plasmodium o. wallikeri is also prevalent in Malaysia [26], while P. o. curtisi infections have recently been reported from Sri Lanka [27]. Interestingly, $P$. $o$. wallikeri has been detected both in human patients and in Western Lowland gorillas in the Central African Republic [28].

Potential differences in pathogenicity of $P . o$. curtisi and P. o. wallikeri are of ongoing interest. An early Spanish study assessing patients from 2005 to 2011 indicated significantly more severe thrombocytopenia in patients with P. o. wallikeri malaria as well as non-significant trends for shorter time periods between infection and onset of clinical symptoms (latency period), lower albumin levels, higher temperature, and more haemolysis markers compared to patients with P. o. curtisi infections [13]. A British study showed geometric mean latency periods of
40.6 days for $P$. o. wallikeri and of 85.7 days for $P$. o. curtisi, with both parasites frequently occurring in patients despite their using chemoprophylaxis during travel compared with Plasmodium vivax or Plasmodium falciparum malaria [15]. A multi-centre study conducted in France, Italy, and Spain recently also suggested $P$. o. wallikeri to be more pathogenic, as defined by associations with more severe thrombocytopenia, coagulopathy as expressed by higher international normalized ratios (INR), and shorter latency in Caucasians.

Further, $P$. o. wallikeri infections were more frequent in males and particularly in Caucasians. However, severe cases were observed for P. o. curtisi as well, and infections with both $P$. $o$. spp. suggested an association with diabetes mellitus and-again-decreased effectiveness of antimalarial drugs as chemoprophylaxis compared with $P$. falciparum [14]. The latter phenomenon might be associated with the geometric mean latency periods and the formation of hypnozoites. Recently, a well-characterized case of a hypnozoite-associated relapse of $P$. o. wallikeri malaria with a strain of identical genotype has been reported [29]. However, few well-documented cases of P. ovale spp. malaria relapses have been published so far [29-31] with a strong dominance of P. o. curtisi [31].

Various PCR approaches for the detection and discrimination of $P . o$. curtisi and $P . o$. wallikeri have been described [18, 32-36], including TaqMan qPCR [18, 3234], semi-nested PCR [37], and nested PCR [38] as well as quantitative and high-resolution melting approaches with detection limits as low as 1 parasite/ $\mu \mathrm{L}$ [39]. Multilocus genotyping has also been applied for $P$. $o$. curtisi and $P$. o. wallikeri discrimination $[23,38]$.

In this study, samples from 77 patients with $P$. ovale spp. malaria returning to Germany between 2010 and 2019 were further differentiated in a retrospective assessment based on two different real-time PCR approaches. Results were compared with patient characteristics to contribute to the scant information available on the possibly differences in aetiological relevance of $P$. o. curtisi and P. o. wallikeri.

\section{Methods}

\section{Aim, design, and setting}

The epidemiology of $P$. o. curtisi and $P . o$. wallikeri in travellers returning to Germany and the available patientrelated information were assessed in a retrospective cross-sectional study over 10 years using clinical information and residual sample materials collected at the 
Bernhard Nocht Institute for Tropical Medicine Hamburg, the German National Reference for Tropical Pathogens, between 2010 and 2019.

\section{Samples}

Residual nucleic acid extractions from EDTA blood samples of all 77 patients with confirmed $P$. ovale spp. infections within the study interval were used, which had been collected and stored at $-80{ }^{\circ} \mathrm{C}$ at the Bernhard Nocht Institute for Tropical Medicine, Hamburg, Germany. The samples were collected between 2010 and 2019. Extractions had been performed using the QIAamp DNA Blood Mini Kit (Qiagen, Hilden, Germany). All samples had been assessed by species-specific real-time PCR before storage (RealStar Malaria S\&T PCR Kit 1.0, altona Diagnostics, Hamburg, Germany), and a subset also by microscopy (Additional file 1).

\section{PCR-based discrimination of $P$. ovale curtisi and $P$. ovale wallikeri}

All DNA samples were analysed using two different published real-time PCR protocols suitable for the discrimination between $P$. o. curtisi and $P$. o. wallikeri. PCR protocol 1 was applied as a duplex real-time PCR using the primers for P. o. curtisi and P. o. wallikeri as described by Bauffe et al. [18] (Additional file 2). The reaction was run on a Corbett RotorGene 6000 or a Corbett RotorGene Q cycler using $20 \mu \mathrm{L}$ volumes with a HotStarTaq Mastermix (Qiagen). The final $\mathrm{MgCl}_{2}$ concentration was adjusted to $3 \mathrm{mmol} / \mathrm{L}$; the applied primer concentrations were $1.6 \mathrm{pmol} / \mu \mathrm{L}$ and the probe concentration $0.1 \mathrm{pmol} / \mu \mathrm{L}$ each. A $5 \mu \mathrm{L}$ volume of extracted DNA was used. Reaction conditions comprised $10 \mathrm{~min}$ at $95^{\circ} \mathrm{C}$ followed by 45 cycles of $10 \mathrm{~s}$ denaturation at $95^{\circ} \mathrm{C}$ as well as annealing and amplification for $30 \mathrm{~s}$ at $60{ }^{\circ} \mathrm{C}$ with subsequent cooling to $40^{\circ} \mathrm{C}$ for $30 \mathrm{~s}$.

PCR protocol 2 consisted of two separate real-time PCRs, one specific for $P$. o. curtisi and the other specific for $P$. o. wallikeri as described by Calderaro et al. [32, 33] (Additional file 2). Again, $20 \mu \mathrm{L}$ volumes were assessed on a Corbett RotorGene 6000 or a Corbett RotorGene Q cycler using the HotStarTaq Mastermix (Qiagen). The optimal final $\mathrm{MgCl}_{2}$ concentration was $3 \mathrm{mmol} / \mathrm{L}$; the primer concentrations were adjusted to $1.2 \mathrm{pmol} / \mu \mathrm{L}$ and the probe concentration to $0.25 \mathrm{pmol} / \mu \mathrm{L}$ each. The amount of extracted DNA used was $2 \mu \mathrm{L}$. Reaction conditions comprised $10 \mathrm{~min}$ at $95{ }^{\circ} \mathrm{C}$ followed by 45 cycles of $15 \mathrm{~s}$ denaturation at $95^{\circ} \mathrm{C}$ as well as annealing and amplification for $60 \mathrm{~s}$ at $60^{\circ} \mathrm{C}$ with subsequent cooling to $40^{\circ} \mathrm{C}$ for $30 \mathrm{~s}$.

The oligonucleotide sequences of the primers, probes, and positive control plasmids are shown in Additional file 2. The positive control plasmids based on pEXA128 vector backbones (eurofins Genomics, Ebersberg,
Germany) were used to prepare rows of 10-fold dilutions in order to calculate detection limits using the program SciencePrimer (http://scienceprimer.com/copy-numbe r-calculator-for-realtime-pcr, last accessed March 8, 2019). For PCR protocol 1, calculated detection limits were $<1$ copy $/ \mu \mathrm{L}$ for $P$. o. wallikeri and 52 copies $/ \mu \mathrm{L}$ for $P$. o. curtisi; for PCR protocol 2, calculated detection limits were 8 copies $/ \mu \mathrm{L}$ for $P$. $o$. wallikeri and 9 copies $/ \mu \mathrm{L}$ for $P$. o. curtisi.

Inhibition control PCRs were not included in these typing PCRs, because inhibition had already been excluded during the initial diagnostic PCR that led to the diagnosis of $P . o$. spp. infection.

\section{Patient characteristics}

All patients were anonymized and the respective clinical data were computer-coded. As far as available, the following data were assessed: gender, age, region of presumed infection, number of days between leaving the endemic country and onset of malaria symptoms, and thrombocyte counts.

\section{Statistics}

Due to the low number of $P$. ovale spp. positive samples, only descriptive analysis was performed. The MannWhitney test was applied to independent parameters as age, latency time, and thrombocyte count using the GraphPad Instat version 3.06 software (GraphPad Software, Inc., San Diego, CA, USA). Matched parameters as Ct-values while comparing both PCR assays were assessed using Wilcoxon's signed ranks test with the help of the open-source software R Commander version 2.53 , which was also used to calculate descriptive parameters like interquartile ranges (IQR).

\section{Ethics}

Ethical clearance was provided by the Ethics Committee of the Medical Association of Hamburg, Germany (registration number WF-012/19), allowing the anonymized assessments to be made without informed consent.

\section{Results \\ Samples}

Residual DNA from 82 diagnostic EDTA blood samples containing parasites of $P$. ovale spp. according to the results of microscopy and PCR was stored at the German National Reference Center for Tropical Pathogens Bernhard Nocht Institute for Tropical Medicine Hamburg (BNITM). The samples had been sent to BNITM from clinicians and laboratories all over Germany for diagnostic verification. Of the 82 samples, 5 represented follow-up samples. Accordingly, first diagnostic samples from 77 independent patients were included in this study. 
Table 1 Summary of the diagnostic results (details in Additional file 1)

Microscopic species identifications

Range of parasitaemia in microscopically positive samples

Ct values of the P. ovale curtisi PCR according to Bauffe et al. (median; IQR)

Ct values of the $P$. ovale curtisi PCR according to Calderaro et al. (median; IQR)

Ct values of the $P$. ovale wallikeri PCR according to Bauffe et al. (median; IQR)

Ct values of the $P$. ovale wallikeri PCR according to Calderaro et al. (median; IQR)
$12 \times$ P. ovale spp., $3 \times$ misidentifications as $P$. vivax,

$40 \times$ Plasmodium spp. without further discrimination,

$17 \times$ not performed

Few visible parasites up to $1 \%$ infected erythrocytes

$24 ; 3$

$26 ; 3$

$25 ; 4$

$28 ; 4.3$

$\mathrm{IQR}=$ interquartile range

Parasitaemia was generally low and ranged from a few visible parasites up to $1 \%$ infected erythrocytes. Initial microscopic identification of $P$. ovale spp. had been successful in 12 samples, while initial misidentification as $P$. vivax had occurred in 3 cases. In the remaining 67 samples, either parasitaemia was insufficient for a qualified microscopic parasite differentiation $(n=40)$ or microscopy had not been performed at the Bernhard Nocht Institute because PCR was requested by the sender of the samples only and the initial microscopic results from the senders' laboratories were unknown $(n=17)$ (Table 1$)$.

\section{Results of the $P$. ovale wallikeri and $P$. ovale curtisi PCRs}

All 77 P. ovale spp. samples were subjected to two different real-time PCR protocols as previously reported [18, 32,33 . The protocols showed $100 \%$ concordance and identified 41 patients with $P$. o. curtisi and 36 patients with $P$. o. wallikeri. Cycle threshold $(\mathrm{Ct})$ values for $P$. $o$. curtisi were $25.4 \pm 3.8$ (mean \pm standard deviation (SD)) with a median of $24(\mathrm{IQR}=3)$ using the PCR of Bauffe et al. and $27.5 \pm 3.9($ mean $\pm \mathrm{SD})$ with a median of 26 $(\mathrm{IQR}=3)$ for the PCR of Calderaro et al. $(\mathrm{P}<0.001)$. For P. o. wallikeri, the Ct values were $24.9 \pm 5.3($ mean $\pm \mathrm{SD})$ with a median of $25(\mathrm{IQR}=4)$ using the PCR of Bauffe et al. and $28.6 \pm 4.2($ mean $\pm \mathrm{SD})$ with a median of 28 $(\mathrm{IQR}=4.3)$ using the PCR of Calderaro et al. $(\mathrm{P}<0.001)$. Differences in Ct value between the two PCR protocols were $1.9 \pm 1.0($ mean $\pm \mathrm{SD})$ with a median of 2 (ranging from 0 to $3, \mathrm{IQR}=2$ ) for P. o. curtisi and $3.6 \pm 2.3$ (mean $\pm \mathrm{SD}$ ) with a median of 3 (ranging from -4 to 11 , $\mathrm{IQR}=2)$ for $P$. o. wallikeri $(\mathrm{P}<0.001)$ (Table 1). Of note, in the five excluded follow-up samples, the Calderaro et al. approach failed to identify one case of $P$. $o$. wallikeri in a post-treatment control that was still positive in the Bauffe et al. approach, but with a relatively high Ct value of 37 .

\section{Patient characteristics}

Of the 77 patients included in the study, gender information was available for 76 participants. Altogether,
53 were male and 23 female. Male-to-female ratios differed considerably between the two groups of $P$. $o$. spp. infections comprising 3.4 and 1.6 for $P$. o. curtisi and $P$. o. wallikeri, respectively. Age information was available for 74 patients. Mean and median age were $31.6 \pm 14.8$ and 29.5 years (IQR $=23.5$ years), respectively, and did not differ significantly between the two patient groups $(\mathrm{P}=0.72)$. Mean age of $P$. o. curtisi-infected patients was 32.5 years with a standard deviation of 15.3 years and was $30.0 \pm 10.8$ years for P. o. wallikeri patients; the median age in both subgroups was 30 years $(\mathrm{IQR}=26.0$ years for $P$. o. curtisi and 20.5 years for $P$. $o$. wallikeri) (Table 2).

Information on travel destinations was documented for 64 patients (32 with P. o. curtisi, 32 with P. o. wallikeri). Results are shown in Table 3 as well as in Additional files 1 and 3. No proven case of malaria relapse was documented.

The time between returning from the travel destinations and the onset of clinical symptoms leading to the diagnosis of malaria (latency period) was documented for 52 patients (27 with $P$. o. curtisi, 25 with $P$. o. wallikeri). Latency periods were $150.9 \pm 232.1$ days (mean \pm SD) with a median of 56.0 days ( $\mathrm{IQR}=153.5$ days) for patients with $P$. o. curtisi and $105.7 \pm 127.9$ days (mean \pm SD) with a median of 58 days $(\mathrm{IQR}=98.0$ days) for patients with $P . o$. wallikeri $(\mathrm{P}=0.80)$ (Table 2, Additional file 1).

Table 2 Characteristics of patients with $P$. ovale curtisi or $P$. ovale wallikeri (details in Additional file 1)

\begin{tabular}{|c|c|c|}
\hline & $\begin{array}{l}\text { Patients } \\
\text { with } P \text {. ovale } \\
\text { curtisi }\end{array}$ & $\begin{array}{l}\text { Patients } \\
\text { with P. ovale } \\
\text { wallikeri }\end{array}$ \\
\hline Male-to-female ratio & 3.4 & 1.6 \\
\hline Age in years (median; IQR) & $30 ; 26.0$ & $30 ; 20.5$ \\
\hline Latency period in days (median; IQR) & $56.0 ; 153.5$ & $58 ; 98.0$ \\
\hline $\begin{array}{l}\text { Thrombocyte count per } \mu \mathrm{L} \text { (median, } \\
\text { IQR) }\end{array}$ & $138.5 ; 105.8$ & $152.0 ; 155.0$ \\
\hline
\end{tabular}

IQR interquartile range 
Table 3 Patients' travel destinations. Data were available for 32 patients with $P$. ovale curtisi and 32 patients with $P$. ovale wallikeri, ( $n$ ) describes the numbers of patients with respective travel destinations

\begin{tabular}{lll}
\hline Travel destination & $\begin{array}{l}\text { Patient with P. ovale } \\
\text { curtisi (n) }\end{array}$ & $\begin{array}{l}\text { Patient with } P . \\
\text { ovale wallikeri } \\
\text { (n) }\end{array}$ \\
\hline Benin & - & 1 \\
Burkina Faso & - & 1 \\
Cameroon & 3 & 7 \\
Equatorial Guinea & 1 & - \\
Gabon & - & 1 \\
Ghana & 5 & 6 \\
Guinea & 2 & - \\
Ivory coast & 1 & 3 \\
Kenya & 1 & 1 \\
Liberia & 2 & - \\
Malawi & 1 & 1 \\
Nigeria & 5 & 2 \\
Papua New Guinea & - & 1 \\
Zambia & 1 & - \\
Sierra Leone & 1 & 1 \\
Somalia & 1 & - \\
Sudan & - & 1 \\
Tanzania & 1 & 2 \\
Togo & - & 1 \\
Uganda & 3 & 2 \\
Various destinations & $4^{\text {a }}$ & $1^{\text {b }}$ \\
\hline Various & $-54 n a t i o n s$ & \\
\hline
\end{tabular}

a Various destinations comprised Benin and the Democratic Republic of the Congo; Nigeria and Gabon; Eritrea, Sudan and Libya; as well as Benin, Togo, Ethiopia, the Philippines and Iran

${ }^{\mathrm{b}}$ Various destinations comprised Mali and the Ivory Coast

Thrombocyte count was available for 10 patients with P. o. curtisi and 9 patients with P. o. wallikeri, with values of $135.1 \pm 56.8 / \mu \mathrm{L}($ mean $\pm \mathrm{SD})$ with a median of $138.5 /$ $\mu \mathrm{L}(\mathrm{IQR}=105.8 / \mu \mathrm{L})$ and $183.1 \pm 114.2 / \mu \mathrm{L}($ mean $\pm \mathrm{SD})$ with a median of $152.0 / \mu \mathrm{L}(\mathrm{IQR}=155.0 / \mu \mathrm{L})$, respectively $(\mathrm{P}=0.40)$ (Table 2, Additional file 1).

\section{Discussion}

The study compared two recently published real-time PCR protocols for the identification and differentiation of P. o. curtisi and P. o. wallikeri in clinical samples. Results of parasite subtyping were correlated with patient characteristics. All patients were travellers returning to Germany from countries known to be endemic for malaria. The results further confirmed previous findings about the high specificity of PCR for the diagnosis of non-falciparum malaria at species level, as several misidentifications during the initial microscopic assessment were corrected. In addition, both real-time PCR protocols that were compared in this study proved to be suitable for the identification of $P . o$ curtisi and $P . o$. wallikeri with $100 \%$ concordance. The protocol of Bauffe et al. [18] was slightly more sensitive than that of Calderaro et al. [32, 33], as suggested by lower Ct values and by a case of failed detection of $P$. o. wallikeri in a post-treatment control sample. Another advantage of the Bauffe protocol was that the assay can be run as a one-well-duplex PCR, while the Calderaro protocol requires two separate PCR assays to distinguish $P$. o. curtisi and P. o. wallikeri. Accordingly, the relatively more sensitive and convenient duplex PCR by Bauffe et al. [18] is the preferred test in this patient population.

Of note, $P$. ovale spp. infections frequently occur in asymptomatic individuals in high endemicity settings [40]. Underlying acquired resistance phenomena have been described as early as in the late 1930s [41, 42]. In the here-described study, only patients were included whose clinical symptoms had triggered diagnostic testing for malaria. Accordingly, no conclusions can be drawn on the diagnostic performance of the applied PCR approaches in patients with completely asymptomatic $P$. ovale spp. infections. From previous studies, however, generally superior sensitivity of PCR compared to microscopy [4345] and alternative modern approaches like mass spectrometry [46] for malaria screening are well documented. Especially, species-specific malaria PCR is considered as more reliable in detecting mixed plasmodial infections in particular in cases with significant differences in density of the different parasite species [44, 47, 48]. Further, PCR is a reliable tool if suboptimal pre-analytic conditions do not allow parasite microscopy, e.g. in case of hemolytic blood [49].

With regard to $P$. ovale spp. epidemiology, the heredescribed assessment clearly confirmed the co-occurrence of $P$. o. curtisi and $P$. o. wallikeri in a wide range of malaria-endemic countries in Sub-Saharan Africa, as already reported $[3,4]$. In contrast to previous reports [13-15], the findings shown here did not support the suggestion of earlier onsets of clinical disease due to $P$. o. wallikeri compared with $P$. o. curtisi [13-15]. Of note, latency could only be assessed for 52 out of 77 patients (67.5\%). Likewise, significant differences in thrombocyte counts were not confirmed. Differences in thrombocyte counts have been reported earlier and were used as an indicator for differences in disease severity. Admittedly, thrombocyte count was available for 19 patients (24.7\%) only. Altogether, the here-described study comprised only half as many samples as the assessment by Nolder et al. [15] but it was of similar size to the multi-national study of Rojo-Marcos et al. [14] comprising 79 patients. However, the latter multicentre study [14] was prospective and thus more robust, while the interpretation of the here-described study is limited by its retrospective 
design. As further limitations, patient characteristics and travel information were documented only for subsets of patients and information on the proportions of travellers visiting friend and relatives as well as of immigrants were no available. Next to this, details on ethnicity, prophylaxis and therapy could not be provided.

\section{Conclusions}

In conclusion, the study confirmed the suitability of two real-time PCR protocols for the discrimination of $P$. ovale spp. into $P$. o. curtisi and P. o. wallikeri as well as the sympatric occurrence of the two species in a wide range of countries in sub-Saharan Africa. In contrast, significant differences in latency periods or thrombocyte counts between patients infected with either of the two parasite species as described previously, were not supported. Admittedly, interpretation of those findings is limited by the low number of available datasets. The $P$. ovale spp. malaria cases reported here were associated with low parasitaemia. Many of them were only PCR-positive, so they probably had submicroscopic malaria. Taken together, from a medical point of view, the results presented here do not support the necessity of $P$. ovale species differentiation into $P$. ovale curtisi and $P$. ovale wallikeri for the clinical management of $P$. ovale spp. malaria patients. Next to this, the data shown here stress the importance of PCR for the diagnosis of P. ovale spp. malaria.

\section{Additional files}

Additional file 1. Details of patients and samples.

Additional file 2. Oligonucleotides used in the P. ovale spp. differentiation PCR platforms.

Additional file 3. Graphical distribution of $P$. ovale curtisi (red dots) and $P$. ovale wallikeri (yellow dots) cases according to countries in which infections were most likely acquired.

\section{Abbreviations}

${ }^{\circ} \mathrm{C}$ : degree centigrade; Ct: cycle threshold; BNITM: Bernhard Nocht Institute for Tropical Medicine; EDTA: ethylenediaminetetraacetic acid; Inc.: incorporated; INR: international normalized ratio; IQR: interquartile range; $\mu \mathrm{L}$ : microlitre; PCR: polymerase chain reaction; pmol: picomole; qPCR: real-time PCR; rRNA: ribosomal ribonucleic acids; SD: standard deviation; spp.: species (plural).

\section{Acknowledgements}

Annett Michel and Simone Priesnitz are gratefully acknowledged for excellent technical assistance and Nancy Lindenberg for her support in data management.

\section{Authors' contributions}

$\mathrm{HF}$ and ET analysed and interpreted the data regarding the PCR results and anonymized clinical information. CW and SR performed microscopic and initial PCR examinations. UL performed the statistical assessments. All authors read and approved the final manuscript.

\section{Funding}

There has been no source of funding for this work.

\section{Availability of data and materials}

All data generated or analysed during this study are included in this published article and its additional files.

\section{Ethics approval and consent to participate}

Ethical clearance was provided by the Ethics Committee of the Medical Association of Hamburg, Germany (Registration Number WF-012/19), allowing the anonymized assessments without informed consent.

\section{Consent for publication}

Not applicable.

\section{Competing interests}

The authors declare that they have no competing interests.

\section{Author details}

${ }^{1}$ Department of Microbiology and Hospital Hygiene, External Site at the Bernhard Nocht Institute, Tropical Microbiology and Entomology, Bundeswehr Hospital Hamburg, Bernhard Nocht Str. 74, 20359 Hamburg, Germany. ${ }^{2}$ Institute for Medical Microbiology, Virology and Hygiene, University Medicine Rostock, Rostock, Germany. ${ }^{3}$ Bernhard Nocht Institute for Tropical Medicine, National Reference Center for Tropical Pathogens, Hamburg, Germany.

Received: 26 May 2019 Accepted: 2 August 2019

Published online: 09 August 2019

\section{References}

1. Phuong MS, Lau R, Ralevski F, Boggild AK. Parasitological correlates of Plasmodium ovale curtisi and Plasmodium ovale wallikeri infection. Malar J. 2016;15:550.

2. Oguike MC, Sutherland CJ. Dimorphism in genes encoding sexual-stage proteins of Plasmodium ovale curtisi and Plasmodium ovale wallikeri. Int J Parasitol. 2015:45:449-54.

3. Putaporntip C, Hughes AL, Jongwutiwes S. Low level of sequence diversity at merozoite surface protein-1 locus of Plasmodium ovale curtisi and $P$. ovale wallikeri from Thai isolates. PLoS ONE. 2013;8:e58962.

4. Ansari HR, Templeton TJ, Subudhi AK, Ramaprasad A, Tang J, Lu F, et al. Genome-scale comparison of expanded gene families in Plasmodium ovale wallikeri and Plasmodium ovale curtisi with Plasmodium malariae and with other Plasmodium species. Int J Parasitol. 2016;46:685-96.

5. Li Y, Wang G, Sun D, Meng F, Lin S, Hu X, Wang S. A case of Plasmodium ovale wallikeri infection in a Chinese worker returning from West Africa. Korean J Parasitol. 2013;51:557-62.

6. Li M, Xia ZG, Tang LH. Overviews on Plasmodium ovale wallikeri and its genetic detection system. Zhongguo Ji Sheng Chong Xue Yu Ji Sheng Chong Bing Za Zhi. 2014;32:64-7 (in Chinese)

7. Li M, Xia Z, Yan H. New type of SSUrDNA sequence was detected from both Plasmodium ovale curtisi and Plasmodium ovale wallikeri samples. Malar J. 2014;13:216.

8. Zhang LL, Ruan W, Chen HL, Lu QY, Yao LN. Identification of five imported cases of Plasmodium ovale wallikeri infection in Zhejiang Province. Zhongguo Ji Sheng Chong Xue Yu Ji Sheng Chong Bing Za Zhi. 2014;32:361-5 (in Chinese)

9. Chu R, Zhang X, Xu S, Chen L, Tang J, Li Y, Chen J, Xuan Y, Zhu G, Cao J, Cheng $Y$. Limited genetic diversity of $\mathrm{N}$-terminal of merozoite surface protein-1 (MSP-1) in Plasmodium ovale curtisi and P. ovale wallikeri imported from Africa to China. Parasit Vectors. 2018;11:596.

10. Jing-Ye S, Li L, Tao Y, Yang L, Xiao-Hong W, Fang H, Yan Z. [Laboratory detection of imported Plasmodium ovale wallikeri in Sichuan Province](in Chinese). Zhongguo Xue Xi Chong Bing Fang Zhi Za Zhi. 2018;30:532-6.

11. Lu F, Ahmed MA, Xu S, Xu S, Han JH, Liu Q, et al. Plasmodium ovale curtisi and Plasmodium ovale wallikeri in Chinese travelers: prevalence of novel genotypes of circumsporozoite protein in the African continent. Infect Genet Evol. 2019;70:9-14.

12. Sun $H$, Li J, Xu C, Xiao T, Wang L, Kong X, et al. Increasing number of imported Plasmodium ovale wallikeri malaria in Shandong Province, China, 2015-2017. Acta Trop. 2019;191:248-51. 
13. Rojo-Marcos G, Rubio-Muñoz JM, Ramírez-Olivencia G, García-Bujalance S, Elcuaz-Romano R, Díaz-Menéndez M, et al. Comparison of imported Plasmodium ovale curtisi and P. ovale wallikeri infections among patients in Spain, 2005-2011. Emerg Infect Dis. 2014;20:409-16.

14. Rojo-Marcos G, Rubio-Muñoz JM, Angheben A, Jaureguiberry S, GarcíaBujalance S, Tomasoni LR, et al. Prospective comparative multi-centre study on imported Plasmodium ovale wallikeri and Plasmodium ovale curtisi infections. Malar J. 2018;17:399.

15. Nolder D, Oguike MC, Maxwell-Scott H, Niyazi HA, Smith V, Chiodini PL, et al. An observational study of malaria in British travellers: plasmodium ovale wallikeri and Plasmodium ovale curtisi differ significantly in the duration of latency. BMJ Open. 2013;3:5.

16. Fuehrer HP, Habler VE, Fally MA, Harl J, Starzengruber P, Swoboda P, et al. Plasmodium ovale in Bangladesh: genetic diversity and the first known evidence of the sympatric distribution of Plasmodium ovale curtisi and Plasmodium ovale wallikeri in southern Asia. Int J Parasitol. 2012;42:693-9.

17. Oguike MC, Betson M, Burke M, Nolder D, Stothard JR, Kleinschmidt I, et al. Plasmodium ovale curtisi and Plasmodium ovale wallikeri circulate simultaneously in African communities. Int J Parasitol. 2011;41:677-83.

18. Bauffe F, Desplans J, Fraisier C, Parzy D. Real-time PCR assay for discrimination of Plasmodium ovale curtisi and Plasmodium ovale wallikeri in the Ivory Coast and in the Comoros Islands. Malar J. 2012;11:307.

19. Alemu A, Fuehrer HP, Getnet G, Tessema B, Noedl H. Plasmodium ovale curtisi and Plasmodium ovale wallikeri in North-West Ethiopia. Malar J. 2013;12:346.

20. Gunawardena S, Daniels RF, Yahathugoda TC, Weerasooriya MV, Durfee K, Volkman SK, et al. Case report of Plasmodium ovale curtisi malaria in Sri Lanka: relevance for the maintenance of elimination status. BMC Infect Dis. 2017;17:307.

21. Dinko B, Oguike MC, Larbi JA, Bousema T, Sutherland CJ. Persistent detection of Plasmodium falciparum, P. malariae, P. ovale curtisi and P. ovale wallikeri after ACT treatment of asymptomatic Ghanaian school-children. Int J Parasitol Drugs Drug Resist. 2013:3:45-50.

22. Chaturvedi N, Bhandari S, Bharti PK, Basak SK, Singh MP, Singh N. Sympatric distribution of Plasmodium ovale curtisi and P. ovale wallikeri in India: implication for the diagnosis of malaria and its control. Trans R Soc Trop Med Hyg. 2015;109:352-4.

23. Miller RH, Obuya CO, Wanja EW, Ogutu B, Waitumbi J, Luckhart S, et al. Characterization of Plasmodium ovale curtisi and P. ovale wallikeri in Western Kenya utilizing a novel species-specific real-time PCR assay. PLoS Negl Trop Dis. 2015;9:e0003469.

24. Diallo MA, Badiane AS, Diongue K, Deme A, Lucchi NW, Gaye M, et al. Nonfalciparum malaria in Dakar: a confirmed case of Plasmodium ovale wallikeri infection. Malar J. 2016;15:429.

25. Diallo MA, Diongue K, Diagne G, Seck MC, Ndiaye M, Dièye B, et al. Plasmodium ovale wallikeri and Plasmodium ovale curtisi malaria in Senegal in 2016. Bull Soc Pathol Exot. 2017;110:286-90 (in French).

26. Liew JW, Mahmud R, Tan LH, Lau YL. Diagnosis of an imported Plasmodium ovale wallikeri infection in Malaysia. Malar J. 2016;15:8.

27. Díaz PB, Lozano PM, Rincón JM, García L, Reyes F, Llanes AB. Quality of malaria diagnosis and molecular confirmation of Plasmodium ovale curtisi in a rural area of the southeastern region of Ethiopia. Malar J. 2015;14:357.

28. Mapua MI, Fuehrer HP, Petrželková KJ, Todd A, Noedl H, Qablan MA, et al. Plasmodium ovale wallikeri in Western Lowland Gorillas and Humans, Central African Republic. Emerg Infect Dis. 2018:24:1581-3.

29. Veletzky L, Groger M, Lagler H, Walochnik J, Auer H, Fuehrer HP, et al. Molecular evidence for relapse of an imported Plasmodium ovale wallikeri infection. Malar J. 2018;17:78.

30. Groger M, Fischer HS, Veletzky L, Lalremruata A, Ramharter M. A systematic review of the clinical presentation, treatment and relapse characteristics of human Plasmodium ovale malaria. Malar J. 2017;16:112.

31. Groger M, Veletzky L, Lalremruata A, Cattaneo C, Mischlinger J, Manego Zoleko R, et al. Prospective clinical and molecular evaluation of potential Plasmodium ovale curtisi and wallikeri relapses in a high-transmission setting. Clin Infect Dis. 2019;1:1. https://doi.org/10.1093/cid/ciz131.

32. Calderaro A, Piccolo G, Perandin F, Gorrini C, Peruzzi S, Zuelli C, et al. Genetic polymorphisms influence Plasmodium ovale PCR detection accuracy. J Clin Microbiol. 2007;45:1624-7.
33. Calderaro A, Piccolo G, Gorrini C, Montecchini S, Rossi S, Medici MC, et al. A new real-time PCR for the detection of Plasmodium ovale wallikeri. PLOS ONE. 2012;7:e48033.

34. Calderaro A, Piccolo G, Gorrini C, Rossi S, Montecchini S, Dell'Anna ML, et al. Accurate identification of the six human Plasmodium spp. causing imported malaria, including Plasmodium ovale wallikeri and Plasmodium knowlesi. Malar J. 2013;12:321.

35. Fuehrer HP, Noedl H. Recent advances in detection of Plasmodium ovale: implications of separation into the two species Plasmodium ovale wallikeri and Plasmodium ovale curtisi. J Clin Microbiol. 2014;52:387-91.

36. Cohen R, Feghali K, Alemayehu S, Komisar J, Hang J, Weina PJ, et al. Use of qPCR and genomic sequencing to diagnose Plasmodium ovale wallikeri malaria in a returned soldier in the setting of a negative rapid diagnostic assay. Am JTrop Med Hyg. 2013;89:501-6.

37. Tanomsing $\mathrm{N}$, Imwong M, Sutherland CJ, Dolecek C, Hien TT, Nosten F, et al. Genetic marker suitable for identification and genotyping of Plasmodium ovale curtisi and Plasmodium ovale wallikeri. J Clin Microbiol. 2013;51:4213-6.

38. Fuehrer HP, Stadler MT, Buczolich K, Bloeschl I, Noedl H. Two techniques for simultaneous identification of Plasmodium ovale curtisi and Plasmodium ovale wallikeri by use of the small-subunit rRNA gene. J Clin Microbiol. 2012;50:4100-2.

39. Joste V, Kamaliddin C, Kendjo E, Hubert V, Argy N, Houzé S. Distinction of Plasmodium ovale wallikeri and Plasmodium ovale curtisi using quantitative polymerase chain reaction with high resolution melting revelation. Sci Rep. 2018;8:300.

40. Roucher C, Rogier C, Sokhna C, Tall A, Trape JF. A 20-year longitudinal study of Plasmodium ovale and Plasmodium malariae prevalence and morbidity in a West African population. PLoS ONE. 2014;9:e87169.

41. Sinton JA. Studies of infections with Plasmodium ovale. V. The effects of multiple inoculations upon the degree and nature of the immunity developed. Trans R Soc Trop Med Hyg. 1940;33:585-95.

42. Sinton JA, Hutton EL, Shute PG. Studies of infections with Plasmodium ovale. Il._-acquired resistance to ovale infections. Trans R Soc Trop Med Hyg. 1939;33:47-68.

43. Frickmann H, Hinz R, Rojak S, Bonow I, Ruben S, Wegner C, et al. Evaluation of automated loop-mediated amplification (LAMP) for routine malaria detection in blood samples of German travelers-a cross-sectional study. Travel Med Infect Dis. 2018;24:25-30.

44. Frickmann $\mathrm{H}$, Wegner $\mathrm{C}$, Ruben $\mathrm{S}$, Behrens $\mathrm{C}$, Kollenda H, Hinz R, et al. Evaluation of the multiplex real-time PCR assays RealStar malaria S\&T PCR kit 1.0 and FTD malaria differentiation for the differentiation of Plasmodium species in clinical samples. Travel Med Infect Dis. 2019;1:1. https://doi.org/10.1016/j. tmaid.2019.06.013.

45. Woldearegai TG, Lalremruata A, Nguyen TT, Gmeiner M, Veletzky L, TazemdaKuitsouc GB, et al. Characterization of Plasmodium infections among inhabitants of rural areas in Gabon. Sci Rep. 2019;9:9784.

46. Christner M, Frickmann H, Klupp E, Rohde H, Kono M, Tannich E, et al. Insufficient sensitivity of laser desorption-time of flight mass spectrometrybased detection of hemozoin for malaria screening. J Microbiol Methods. 2019;160:104-6.

47. Shokoples SE, Ndao M, Kowalewska-Grochowska K, Yanow SK. Multiplexed real-time PCR assay for discrimination of Plasmodium species with improved sensitivity for mixed infections. J Clin Microbiol. 2009:47:975-80

48. Grossman T, Schwartz E, Vainer J, Agmon V, Glazer Y, Goldmann D, et al. Contribution of real-time PCR to Plasmodium species identification and to clinical decisions: a nationwide study in a non-endemic setting. Eur J Clin Microbiol Infect Dis. 2017;36:671-5.

49. Hagen RM, Hinz R, Tannich E, Frickmann H. Comparison of two real-time PCR assays for the detection of malaria parasites from hemolytic blood samples_-Short communication. Eur J Microbiol Immunol (Bp). 2015;5:159-63.

\section{Publisher's Note}

Springer Nature remains neutral with regard to jurisdictional claims in published maps and institutional affiliations. 